\title{
La cuestión del agua en La Gomera: síntesis de un proceso de expropiación al campesinado (1900-1950)
}

\author{
Luis Manuel Jerez y Víctor Onésimo Martín Martín
}

\begin{abstract}
PALABRAS CLAVE: La Gomera, dula, comunidad de regantes, expropiación.
\end{abstract}

CÓDIGOS JEL: Q10, Q15, Q19, Q25.

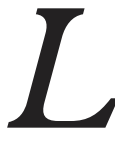

os estudios sobre la gestión y uso de un recurso tan importante como el agua en Canarias son escasos y de difícil elaboración, dadas las singularidades insulares y la escasez y dificultad de acceso a las fuentes documentales. Aqui se propone un estudio de caso referido a la isla de La Gomera. En esta isla el uso y aprovechamiento del agua se había gestionado históricamente a través del sistema de la dula, pero a comienzos del siglo XX se cambió por el de turno de horario y de apropiación de sobrantes. Se sostiene que este cambio se debió al paulatino triunfo de los intereses de los grandes propietarios de la tierra, quienes necesitaban controlarla para expandir los nuevos cultivos de exportación en la costa (plátanos y tomates). Tras consultar los expedientes sobre alumbramientos, concesiones y creación de comunidades de regantes, y los proyectos sobre aprovechamientos de aguas que obran en el Archivo Histórico del Consejo Insular de Aguas de La Gomera, los documentos de escrituras del Registro de la Propiedad de San Sebastián de La Gomera, el Catastro de Rústica y diversos expedientes conservados en el Archivo Histórico Provincial de Santa Cruz de Tenerife, concluimos que se trató de un proceso de expropiación resuelto en la primera mitad de la centuria pasada y que se materializó siguiendo dos formas: la corporativa, aplicada en los valles del norte y oeste a través de la creación de las comu- 
nidades de regantes; y por apropiación directa en el sur, mediante el empleo de las concesiones administrativas.

\section{Accessing water on La Gomera: an overview of a peasant expropriation process (1900-1950)}

\section{KEYWORDS: La Gomera, dula, irrigation association, expropriation.}

\section{JEL CODES: Q10, Q15, Q19, Q25.}

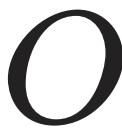

$n$ the Canary Island of La Gomera the use and exploitation of water was historically managed via the dula system until, in the early twentieth century, it was undermined by the interests of large scale landowners in their attempt to control water so as to extend their new export crops: bananas and tomatoes. Documentation for this study stems from sources such as the Archivo Histórico del Consejo Insular de Aguas de La Gomera, the Registro de la Propiedad de San Sebastián de La Gomera, the Catastro de Rústica and the Archivo Histórico Provincial de Santa Cruz de Tenerife. The information examined suggests that this can be considered an expropriation process settled during the first half of the century, following two channels: by corporative means that led to irrigation associations in the valleys of the north and west, or by direct appropriation through administrative concessions in the south.

Recepción: 2016-02-02 - Revisión: 2016-11-20 - Aceptación: 2016-11-22

Luis Manuel Jerez es doctor en Geografía por la Universidad de La Laguna. Desempeña labores de investigación social en el marco de dicha universidad como miembro del grupo de investigación consolidado de la ULL Grupo de Investigación sobre el Subdesarrollo y el Atraso Social (GISAS), así como una actividad profesional en el campo del urbanismo, la ordenación territorial y el desarrollo e implantación de las TIG (Tecnologías de la Información Geográfica) en diversos proyectos con organismos públicos. Dirección para correspondencia: c/ Evaristo Ramos, 17, 3. ${ }^{\circ}$ H, 38009 Santa Cruz de Tenerife (España).C.e.:luismjd@hotmail.com

Víctor Onésimo Martín Martín es doctor en Geografía por la Universidad de La Laguna y profesor titular de Análisis Geográfico Regional del Departamento de Geografía e Historia de la Universidad de La Laguna. Coordinador del grupo de investigación consolidado de la ULL denominado Grupo de Investigación sobre el Subdesarrollo y el Atraso Social (GISAS). Dirección para correspondencia: c/ San Germán, 13, Residencial Andrea, viv. 52, 38205 La Laguna (Santa Cruz de Tenerife, España). C. e.: vbmartin@ull.es 


\section{INTRODUCCIÓN}

Nada fácil ha sido en España -ni sigue siendo- todo lo que ha tenido que ver con la gestión y aprovechamiento del agua. Se trata de una problemática de profundas raíces históricas que, en su devenir, ha desembocado en la actualidad mostrándose bajo nuevos ropajes adaptados al contexto social y económico imperante. En el fondo se asienta una cuestión fundamental, que no es otra que la forma de propiedad del agua, bien sea comunal, bien sea privada.Y alrededor de esta antinomia se ha articulado buena parte de los modelos de gestión y legislaciones hidráulicas establecidos en el periodo contemporáneo. Por citar algunos ejemplos: los modelos históricos de gestión comunal (adulamientos y heredamientos) o las leyes de Aguas de 1866 y 1879, como articulados para concretar la titularidad y formas de gestión y aprovechamiento de las aguas.

En este sentido, la isla canaria de La Gomera ha sido un escenario pequeño, pero ilustrativo, de la dialéctica de ambas formas de propiedad y gestión (comunal y privada). Una contradicción que se intensificaba en función de la importancia que adquiría el recurso agua dentro de la coyuntura económica sobrevenida (expansión de la agricultura de exportación), y que fue derivando en un proceso de crisis del modelo comunal en favor de los sistemas corporativos y privatizadores impulsados por los viejos y nuevos grandes propietarios de la isla a lo largo del siglo $\mathrm{xx}$.

Consideramos, por tanto, que los apartados que siguen contribuirán al esclarecimiento de la compleja y heterogénea realidad histórica en torno al agua en España, teniendo en cuenta la singularidad que representan los espacios insulares como el nuestro dentro del país, tanto desde el punto de vista geográfico como histórico.

\section{LA APORTACIÓN DE LA GOMERA A LA COMPRENSIÓN DE LA GESTIÓN DE LOS BIENES COMUNALES: ESTADO DE LA CUESTIÓN E HIPÓTESIS}

Desde que a finales de los años sesenta del pasado siglo se publicara el artículo de Garrett Hardin (1968), La tragedia de los comunes, han sido muchísimos los trabajos de investigación dedicados a analizar los bienes comunales, tanto para su defensa como para justificar su desaparición. Además de la alternativa de la privatización, Hardin sostenía la necesidad de la intervención de una institución externa que mitigara el individualismo de los usuarios de los bienes comunales en aras de que el recurso comunal no desapareciera a causa de su sobreexplotación. 
En publicaciones posteriores y más recientes se ha comenzado a matizar, en unos casos, y a criticar, en otros, las conclusiones del trabajo de Hardin. Así, en uno de los libros más sugerentes que se han escrito sobre la propiedad comunal, Governing the Commons, Elinor Ostrom ${ }^{1}$ intentaba demostrar que la propiedad comunal no sólo no estaba condenada a desaparecer, sino que ofrecía valiosos ejemplos históricos de gestión adecuada y sostenible de los recursos naturales a través de las propias instituciones socioeconómicas que los gestionaban desde hacía siglos (Ostrom, 1990).

El trabajo de Ostrom se nutrió de una amplia muestra de casos locales con el objetivo de basar su teoría sobre el éxito de la acción colectiva. Varios de esos ejemplos empíricos los proporcionaron las comunidades de regantes del este de España (Valencia, Alicante, Murcia u Orihuela), de modo que, como señala Garrido (2014), los sistemas de riego de las huertas españolas, que ya habían sido objeto de interés para los ingenieros británicos y franceses en el siglo XIX, pasaron a ser mencionados con cierta frecuencia en la literatura reciente sobre los recursos comunales y su gestión (Garrido, 2011).

De acuerdo con la terminología utilizada por Ostrom, las huertas en las que el agua pertenece al conjunto de regantes, las pesquerías y los pastos de gestión comunal, son ejemplos de recursos de aprovechamiento común (common pool resources); es decir, son conjuntos de recursos (resource systems), naturales o creados por el hombre, lo bastante grandes como para hacer que sea difícil, pero no imposible, que quienes tienen derecho a aprovecharlos en común puedan vigilar cómo son utilizados.

La tragedia de los comunes hardiniana sólo podría ser evitada mediante su privatización o mediante su gestión por parte del Estado. Ostrom señala la inviabilidad de la privatización en muchos casos, y concluye que los costes de supervisión tenderán a ser más bajos si la vigilancia es realizada por los propios usuarios del sistema que si la realiza una autoridad externa, a condición de que las reglas del juego también hayan sido diseñadas por los propios usuarios. Los pioneros trabajos sobre las comunidades de regantes del este peninsular de la escuela anglosajona (Glick, 1970; Maass \& Anderson, 1978) sirvieron de fuente a la teoría de Ostrom. Como resultado -señala Garrido (2011)-, Ostrom dio por supuesto que en los regadíos españoles concurrían ocho circunstancias o principios de éxito $^{2}$ que, sin embargo, los más reputados especialistas españoles en la ma-

1.Premiada en 2009 con el Premio Nobel de Economía por sus trabajos relacionados con la gobernanza, especialmente de los recursos compartidos.

2.Fronteras claramente definidas; congruencia entre reglas de apropiación, reglas de restauración y condiciones locales; acuerdos colectivos; supervisión; sanciones proporcionadas; mecanismos para la resolución de conflictos; disfrute de un mínimo reconocimiento del derecho a autoorganizarse; estructura anidada. 
teria defienden que no estaban presentes (Pérez Picazo, 2001; Peris, 1997; Romero \& Mateu, 1991).

Garrido concluye con una crítica mesurada, tanto hacia las conclusiones de Hardin como a las de Ostrom: la propiedad comunal no está condenada a sufrir ninguna inevitable "tragedia", pero tampoco parece adecuado contemplarla de manera excesivamente idealizada; como la gestión sostenible de los comunales exige -entre otras cosas- que no todos puedan acceder a ellos, la presencia de instituciones comunales vigorosas puede ser compatible con la de muchos excluidos y con una elevada desigualdad social. De hecho, concluye este autor, la sociedad que acogía a las comunidades de regantes analizadas en su artículo se caracterizó, sobre todo antes del siglo xx, por la fuerte desigualdad en el reparto de la propiedad de la tierra de las huertas, una propiedad de carácter privado que era la que daba el derecho a utilizar el agua común.

Si bien es verdad que bastantes de los ocho principios establecidos por Ostrom se daban en los sistemas de riego de los valles de La Gomera, concluimos con Garrido en sus investigaciones peninsulares que en las comunidades de regantes y adulamientos de esta isla existía una fuerte desigualdad en el reparto de la propiedad de la tierra y, por tanto, del agua. Una realidad que no sólo se dio antes del siglo xx, sino que prosiguió y se amplió a lo largo de esa centuria. Como afirmación al respecto, exponemos los datos del análisis que hemos realizado del Catastro de Rústica, que es la fuente que aporta la información más antigua de la estructura de la propiedad en la isla ${ }^{3}$.

TABLA 1

Número de propietarios y superficie por grupos de propiedad, 1957

\begin{tabular}{lcrrr}
\hline & Propietarios & \multicolumn{1}{c}{$\%$} & Hectáreas & $\%$ \\
\hline Pequeña & 10.302 & 90,4 & 9.080 & 26,2 \\
Mediana & 908 & 8,0 & 8.109 & 23,4 \\
Grande & 181 & 1,6 & 17.447 & 50,4 \\
Total & $\mathbf{1 1 . 3 9 1}$ & $\mathbf{1 0 0 , 0}$ & $\mathbf{3 4 . 6 3 7}$ & $\mathbf{1 0 0 , 0}$ \\
\hline
\end{tabular}

Fuente: elaboración propia a partir del Catastro de Rústica de 1957.

3.La clasificación en grupos de la propiedad territorial siempre ha sido una cuestión compleja. En el caso canario, Román (1996: 110) apunta que tal inconveniente se debe a las características geográficas de las islas y al vacío de fuentes documentales al respecto. Esto ha supuesto -según el autorque la bibliografía que estudia los cambios en los grados de concentración territorial sea escasa en Canarias. Nosotros, aplicando un criterio superficial, hemos definido los siguientes grupos de propietarios: pequeños propietarios (con menos de 5 hectáreas); medianos propietarios (entre 5 y 20 hectáreas); grandes propietarios (más de 20 hectáreas). 
Además, a pesar de esas enormes desigualdades, dichas comunidades, tanto en el este peninsular como en La Gomera, han sobrevivido hasta hoy. De hecho, fue el crecimiento de la demanda de los productos hortofrutícolas canarios por parte de los mercados extranjeros lo que acrecentó la reorganización de la estructura de la propiedad (relatifundización) y, con ello, el intento de los viejos y nuevos grandes propietarios por hacerse con una parte sustancial del tradicional recurso comunal del agua de riego. Por tanto, los sistemas agrarios tradicionales de regadío, donde el agua era comunal, fueron experimentando un proceso de control, en unos casos, y de privatización, en otros, de este recurso a favor de los grandes propietarios y en detrimento del pequeño campesinado. Esta conclusión, como veremos, podemos aplicarla al caso de La Gomera, isla en la que, si sobrevivió en algunos valles la gestión comunal del agua, fue gracias a las luchas campesinas sostenidas contra sus intentos de apropiación por parte de la terratenencia insular.

\section{3. ÁMBITO TERRITORIAL Y FUENTES DE ESTUDIO}

La Gomera es un territorio particular no sólo por su carácter insular, sino también por ser un espacio escasamente conocido en el marco de las ciencias sociales. Dentro de Canarias presenta bastantes peculiaridades con respecto a otras islas en lo que a las formas de aprovechamiento de los recursos se refiere, y, en este sentido, el agua es uno de ellos.

La escasa atención que ha prestado la ciencia a la cuestión del agua en esta isla nos ha empujado a abordar este artículo como un intento de profundización en este tema, el cual permita alumbrar una realidad que, hasta el momento, es bastante imprecisa y confusa, pues los trabajos que la han tratado sólo lo han hecho de manera tangencial.

\section{1. Ámbito de estudio y distribución territorial del agua}

La isla de La Gomera, con una superficie aproximada de $373 \mathrm{~km}^{2}$, es la segunda isla más pequeña del archipiélago canario. Se encuentra dividida en seis municipios: Agulo, Alajeró, Hermigua, San Sebastián, Valle Gran Rey y Vallehermoso, cuyas cabeceras municipales se encuentran ubicadas en los valles más importantes, a excepción de Agulo, situado al pie de un impresionante acantilado, y Alajeró, en las medianías ${ }^{4}$ del municipio.

4.En Canarias las medianías identifican a la franja situada entre los 500-900 metros de altitud, donde tradicionalmente se desarrolló el policultivo de secano, que pudo ser regado gracias a la humedad aportada por los vientos alisios que afectan a las islas. En todo caso, ese intervalo varía en función de la vertiente en la que nos encontremos. Así, en la de barlovento la zonificación podría es- 


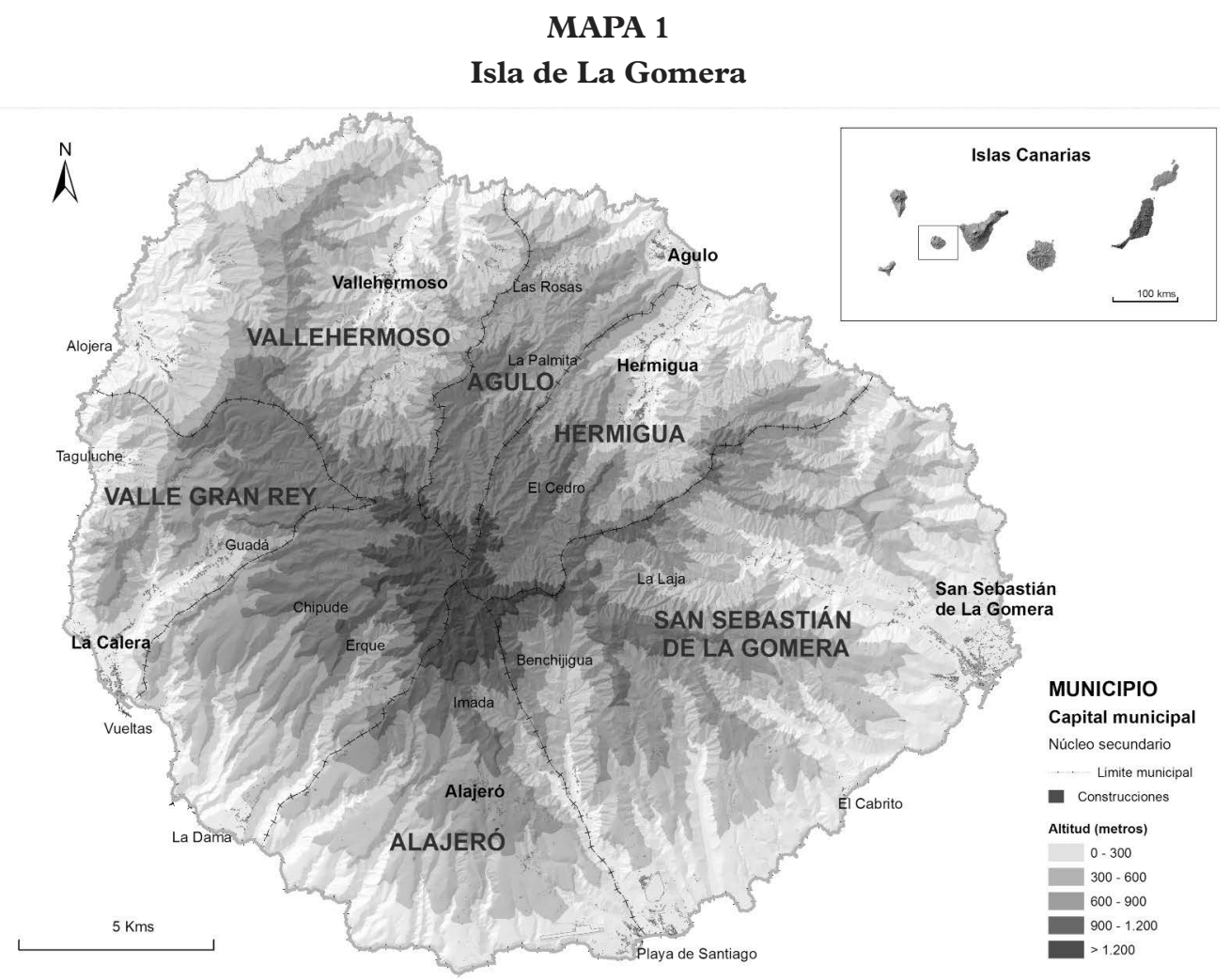

Fuente: elaboración propia a partir de la base cartográfica de Grafcan.

La altitud que alcanza la isla (con cota máxima a 1.487 metros en el pico de Garajonay) es el factor que permite la retención de los vientos alisios y la descarga de buena parte de la humedad que transportan. Esa humedad, presente en forma de niebla, es captada por la masa forestal, dando lugar a un intenso goteo de agua llamado lluvia horizontal. Junto a esta agua, la isla también se nutre de la aportada por las borrascas que afectan durante el invierno, así como por la de otras precipitaciones ocurridas en distintas épocas del año ${ }^{5}$. Todas ellas, en su conjunto, constituyen las aguas de la isla, de las que una parte discurre superficialmente y otra se filtra por el sustrato rocoso hasta concentrarse en el acuífero. Asimismo, de ésta última, una porción fluye al exterior por fuentes o nacientes naturales, que en su mayor parte se localizan dentro de los barrancos, allí donde el nivel de incisión ha

tablecerse entre los 400-900 metros, y en la de sotavento, entre los 600-1.000.

5.Según los datos del Plan Hidrológico Insular (Consejo Insular DE Aguas DE La Gomera, 2001: 53), la cantidad de agua precipitada sobre La Gomera, prescindiendo de la lluvia horizontal, asciende a unos $137 \mathrm{hm}^{3}$ de media anual. 
descubierto el curso de las aguas subterráneas. Por este motivo, la red hidrográfica se constituye como el factor estructural sobre el que bascula el aprovechamiento del agua en La Gomera, pues además de abrir los nacientes, los barrancos también son los canales naturales por los que discurren las aguas de lluvia que posteriormente se emplean para el riego.

\subsection{Un tema poco estudiado: la relevancia de las fuentes directas}

El estudio de la cuestión del agua en La Gomera resulta un trabajo arduo y complejo de abordar, tanto por su propia naturaleza (titularidad) como por la organización y modos de gestión, a lo que habría que añadir la escasez de investigaciones al respecto para la isla, pues en ella la economía del agua ha sido distinta a la desarrollada en otras islas del archipiélago canario, como Tenerife, La Palma ${ }^{6}$ o Gran Canaria. A diferencia de La Gomera, en dichas islas sí que se dio un evidente y transparente proceso de privatización, el cual se fue desarrollando legalmente desde el siglo Xvi (Gómez Gómez, 2010; Díaz Cruz, 2013), aunque no fue hasta el siglo XIX cuando se consolidó a través de las desamortizaciones y diferentes disposiciones normativas que culminaron con la ley de Aguas de 1879 (Macías, 1990).

Para nuestro ámbito de estudio, sólo los trabajos de Reyes $(1985,1989)$ aportan algo de luz sobre el tema, pero, aun así, sin aclarar muchas realidades. Hablamos, por tanto, de una materia prácticamente desconocida en la isla y que hemos podido descifrar, en la medida de lo posible, en un apartado de nuestra tesis doctoral (Jerez, 2015), del cual hemos querido extraer algunas de las conclusiones más destacadas para elaborar este artículo y explicar el proceso de paulatina expropiación del agua al campesinado por parte de los grandes propietarios de la tierra.

La diversidad de fuentes empleadas no es tan prolija como pudiera pretenderse. El desarrollo de este estudio ha contado con las fuentes necesarias, pero, sobre todo, accesibles para abordarlo. Tal es así, que hay municipios, como Vallehermoso, de los que casi no existen documentos que nos alumbren acerca del proceso histórico en torno al agua. En todo caso, con las fuentes disponibles hemos sido capaces de tejer un corpus argumental en torno a ese proceso de expropiación. Para ello, acudimos al empleo de todo tipo de expedientes sobre alumbramientos, concesiones y creación de comunidades de regantes, a los proyectos sobre aprovechamientos de aguas y al Plan Hidrológico Insular

6.En el municipio de Los Sauces de esta isla pervivió un sistema de aprovechamiento comunal del agua asignada a la tierra similar a La Gomera, que ha sido estudiado en la tesis doctoral del antropólogo José Antonio BATISTA (2001). 
que obran en el Archivo Histórico del Consejo Insular de Aguas de La Gomera (en adelante, AHCIALG); a los documentos de escrituras del Registro de la Propiedad de San Sebastián de La Gomera; al Catastro de Rústica (1957 y 2001); a diversos expedientes conservados en el Archivo Histórico Provincial de Santa Cruz de Tenerife; y a las tradicionales fuentes hemerográficas, bibliográficas y cartográficas propias de una investigación de esta naturaleza. Con el uso de todas ellas trataremos de dejar constancia empírica de la estrategia seguida por los grandes propietarios de la tierra para hacerse con el control del agua comunal (pública) en La Gomera, ya fuese a través de la conformación de las comunidades de regantes como de la "privatización» directa a partir de las concesiones administrativas.

\section{ANTECEDENTES HISTÓRICOS SOBRE LA TITULARIDADY GESTIÓN DEL AGUA EN LA GOMERA}

Atendiendo a la titularidad de las aguas en La Gomera, cabe decir que éstas se dividen actualmente en privadas y públicas. Las primeras son las conformadas por las aguas extraídas de los pozos o nacientes privados, es decir, aquellos que están ubicados en las parcelas que son propiedad de un agente particular no integrado en una dula ${ }^{7}$ o comunidad de regantes ${ }^{8}$. Más compleja es la delimitación de las aguas públicas, ya que en ellas se engloban, tanto las que están controladas por el Estado (ayuntamientos, Cabildo y Consejo Insular de Aguas) como las aguas comunales, es decir, aquellas sobre las que recaen una serie de derechos consuetudinarios de aprovechamiento. Las pertenecientes al Estado derivan de la reorganización político-administrativa nacida al calor de la Constitución de 1812, por la que todas las aguas que nacían en la cumbre (zona de monte, antes propiedad del señorío) pasaron a manos de los ayuntamientos, al igual que la tierra. Junto a éstas, también se incluyen las superficiales que discurren por los cauces públicos y que están exentas de uso comunal (buena parte de ellas se concentran en las presas y embalses públicos), así como las subterráneas. Por su parte, las aguas comunales son las que siguen estando vinculadas a la tierra, bien se mantengan en régimen de dula, o bien se encuentren gestionadas por una comunidad de regantes. Sobre ellas, el Estado no tiene atribuciones, sólo los regantes de la dula o comuneros.

7.Fue el sistema de riego tradicional en la isla, del que ya hablaremos en un apartado específico.

8.Con la ley canaria de Aguas de 1990 todas las aguas pasan a ser de dominio público, por lo que la captación de aguas superficiales y el alumbramiento de las subterráneas requiere de una concesión administrativa (art. 73.2). En este sentido, las aguas que anteriormente a esta ley figuraban como privadas, si actualmente sus propietarios deciden registrarlas, se convertirán en aguas de dominio público, aunque la ley no les impide que sigan siendo privadas, siempre y cuando sus titulares no las inscriban en el Registro y Catálogo de Aguas elaborado por el Consejo Insular de Aguas. 
Las aguas comunales nunca han sido propiedad de nadie en particular, sino que su aprovechamiento, su uso, ha estado ligado a la tierra en sí misma, a la parcela de riego, y no a su propietario. De este hecho se tiene constancia, por lo menos, desde el siglo XVI. Esta forma antigua de uso perdura en la actualidad únicamente en las zonas afectadas por una dula, dado que en las gestionadas por las comunidades de regantes, si bien no están sometidas a ningún título de propiedad -ni siquiera por las propias comunidades regantes-, esa cualidad comunal se fue desdibujando a lo largo de la primera mitad del siglo $\mathrm{xx}$ con el proceso de expropiación dirigido por los grandes propietarios de la tierra que controlaban dichos organismos de riego, aspecto que veremos con detalle más adelante. Antes, expliquemos de manera sintética cuáles fueron los antecedentes históricos que desembocaron en ello.

\section{MAPA 2}

\section{Sistemas de riegos actuales en La Gomera}

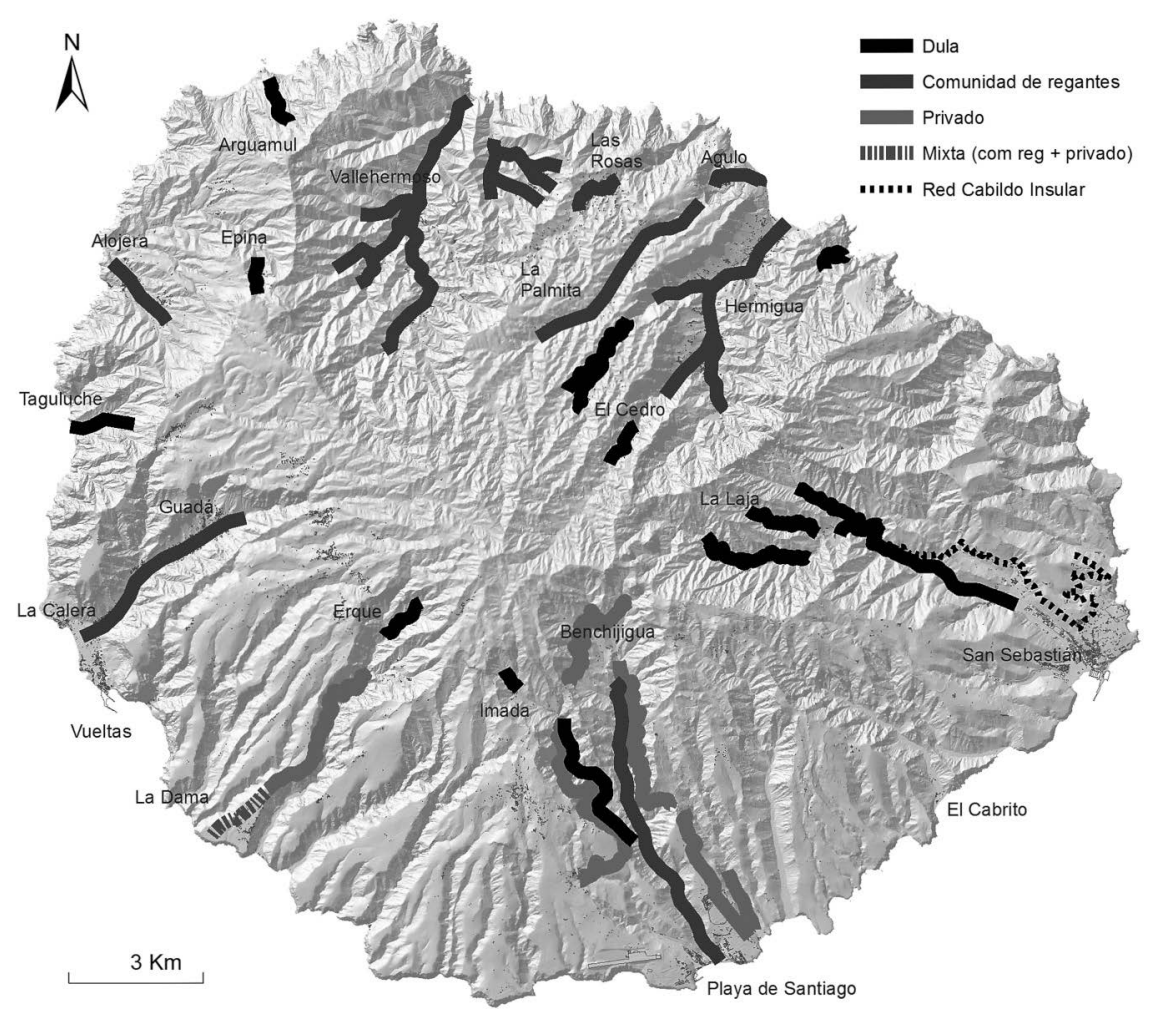

Fuente: elaboración propia a partir de la base cartográfica de Grafcan. 


\subsection{El proceso en el Antiguo Régimen}

Con el proceso de conquista abierto en el siglo Xv e implantación del señorío a finales de esa misma centuria en La Gomera, el recurso del agua, al igual que el de la tierra, pasó por primera vez a ser de titularidad señorial. Lo que hasta entonces en la comunidad aborigen era un recurso de libre disposición, se convirtió en un bien monopolizado por la nueva institución que se adueñó del espacio insular (Díaz Padilla \& RodríguezYanes, 1990: 158; Gómez Gómez, 2010: 115). Ese hecho marca el punto de arranque del control feudal de ambos recursos, el de su titularidad señorial.

Con la consiguiente repoblación de la isla se fueron articulando una serie de estrategias de uso y gestión de las aguas vinculadas a los repartimientos y a las cesiones de tierras. La empresa de asentar nuevos pobladores en la isla (colonos) requería de la entrega de tierras. En La Gomera, ese proceso tuvo muchas similitudes al ocurrido en las llamadas islas de realengo (Tenerife, La Palma y Gran Canaria); es decir, el señorío fue cediendo tierras por toda la geografía insular, bien en propiedad, bien en enfiteusis, o bien en arriendo u otras formas indirectas de explotación. Y junto a la tierra, los señores asignaban el uso -no la propiedad- del agua para su riego. Por este motivo, en algunos lugares de la isla cobraban una renta en especie por el uso del agua. Un ejemplo fue el del valle de Benchijigua ${ }^{9}$, donde atributaban a los pequeños propietarios de la zona por el uso de las aguas que traspasaban los límites de la propiedad señorial; un procedimiento que también aplicaron en otros espacios, como La Laja, el barranco de San Sebastián o Hermigua (Díaz Padilla \& Rodríguez Yanes, 1990: 159).

Con el transcurso del tiempo, ese uso del agua vinculado a la tierra fue adoptando la forma de derecho, siendo en este marco en el que tuvo cabida la dula como sistema de riego principal. Por tanto, durante el período señorial (siglos XV-XIX) se combinaron dos formas en torno a la propiedad del agua en La Gomera: la privada (del señorío y de particulares) ${ }^{10}$, asentada desde los inicios de la conquista; y la comunal, resultante de un derecho de uso consuetudinario vinculado a la tierra (dula).

Hablamos, entonces, de un proceso que no difiere mucho de lo sucedido en el resto de las islas del archipiélago. Para el caso canario, Macías apunta que, frente a la tesis que señala un derecho de propiedad privada burgués implantado desde el momento mismo de la colonización de Canarias (conquista señorial o realenga), más bien se trataba de un

9.Situado en el sur de la isla y muy rico en agua, fue propiedad del señorío.

10.El agua privada vinculada a la propiedad alodial era la extraída mediante pozos en el interior de sus fincas. 
característico régimen feudal de propiedad en el que existía una dualidad de dominios: los señores y los delegados regios cedían el dominio útil a sus respectivas comunidades para su prioritario uso comunal (Macías, 1990: 123-125). Será ese régimen feudal de propiedad el que se ponga en cuestión cuando en el siglo XIX se desarrollen las reformas liberales en el contexto de la denominada revolución burguesa: tragedia del uso comunal del agua con la consecuente privatización del recurso, que fue pasando a manos de los aguatenientes (Macías, 2000). Concretamente, en La Gomera los mecanismos empleados por los grandes propietarios para apropiarse de las aguas comunales siguieron dos formas, a saber: la creación de comunidades de regantes (dominadas por los terratenientes) y la obtención de concesiones administrativas. Ambas fueron las estrategias utilizadas por ese minoritario grupo para expropiar paulatinamente las aguas superficiales al pequeño campesinado gomero.

\subsection{La creación de las comunidades de regantes}

Con la abolición de los señoríos jurisdiccionales en 1811 y la aparición de las leyes de aguas de 1866 y 1879 , se sentaron las bases de la regulación del agua llevada a cabo en España a lo largo de la siguiente centuria (Martín-Retortillo, 1965: 11), hitos que, si bien tuvieron repercusión en La Gomera, no terminaron de desprenderse de la ambigüedad heredada de la etapa anterior, situación que se ha prolongado hasta el presente.

Las iniciativas reformistas decretadas el 6 de agosto de 1811 por las Cortes de Cádiz suprimieron el dominio eminente de los señores sobre las aguas. Un año después, la Constitución de 1812 determinó que todas las aguas nacidas en la zona de monte pasasen a manos de los ayuntamientos, los cuales se convirtieron en los nuevos titulares de la mayor parte de la masa boscosa de la isla (las cumbres). Eran los primeros pasos para intentar superar el modelo patrimonial del agua y su sustitución por regímenes de propiedad plena enajenable (Calatayud, 2016). El hecho de que el agua ahora pasara a manos del Estado (ayuntamientos) iba a influir también en la comunal, la adscrita a la tierra, la empleada por los distintos adulamientos existentes en los principales valles de la isla, y que también sufriría las incidencias de esos impulsos reformistas. En este sentido, consideramos que la proliferación de los heredamientos ${ }^{11}$ (heredades de aguas) en el XIX fue un punto de arranque. Según Quirantes (1981: 91), fue en esa centuria cuando se multiplicaron los heredamientos, primero tradicionales ${ }^{12} \mathrm{y}$, posteriormente, de nueva crea-

11.Agrupaciones de diferentes regantes que utilizaban el agua de un mismo manantial o arroyo, y cuyo objetivo no era otro que la ordenación y buen aprovechamiento de las aguas.

12. Tomando como referencia el estudio de Alejandro NiETo (1967), Reyes apunta que no se puede 
ción, los cuales se transformaron en comunidades de regantes en la primera mitad del siglo XX. Asimismo, dicho autor afirma que los procesos desamortizadores fueron la causa de tal incremento, dado que favorecieron el acceso a la tierra a multitud de personas, provocando un crecimiento poblacional en la isla. Aunque seguramente estos dos últimos aspectos (acceso a la tierra y crecimiento demográfico) sean consecuencia del intento de los viejos y nuevos heredamientos de confirmar todos los derechos preexistentes ante la nueva legislación decimonónica sobre el agua, y ante la creciente demanda generada por los nuevos cultivos de exportación (Macías \& Ojeda, 1989).

En la culminación de este periodo transicional situamos las dos leyes que se redactaron en la segunda mitad del siglo XIX, con las que se abría una nueva etapa en la regulación del uso y gestión del agua. La primera fue la ley de 1866, con la que se delimitó el dominio público, a saber: todas las corrientes naturales, los cauces y las riberas de los ríos (en nuestro caso, los barrancos), quedando fuera de él las aguas subterráneas. El testigo de esa ley lo tomó la de 1879, la cual abría la puerta al aprovechamiento privativo del agua (mediante las concesiones administrativas) y a la generación de comunidades de regantes (como entes particulares con facultades sancionadoras). Sería esta ley la que sentase las bases fundamentales del proceso de expropiación del agua comunal a los campesinos en la siguiente centuria. Así, con la aparición de la primera comunidad de regantes en 1916, se estableció un nuevo orden en la forma de uso y gestión de las aguas comunales en La Gomera, pues a partir de su constitución serían estos organismos (controlados por los grandes propietarios) los encargados de administrar el agua de la cuenca en la que se insertaban.

\subsection{Las concesiones administrativas}

$\mathrm{Al}$ calor de los preceptos de esas leyes y otros dispositivos legales se desencadenaron procesos de auténtica privatización de dichas aguas en el sur de la isla a manos de agentes foráneos vinculados al negocio agroexportador.

En este sentido, y esto es extensible a toda Canarias, se produce un refinamiento de los mecanismos de control progresivo del agua heredados del Antiguo Régimen por parte de la oligarquía terrateniente (agrupada en la institución de los heredamientos de aguas): nuevos caudales obtenidos gracias al control de los órganos del Estado (delegados regios

afirmar con rotundidad que los heredamientos tradicionales que existieron en La Gomera a finales del siglo XVIII y principios del XIX fueran de la misma naturaleza que los desarrollados en las islas de Tenerife, Gran Canaria y La Palma, los cuales se remontaban a los siglos XV y XVI; lo que indica que no fueron fruto de los primeros repartimientos efectuados con la conquista (REYES, 1989: 28-32). 
y gobernadores), usurpación y conversión del agua señorial o realenga en agua de los concejos para luego pasar a aguas de propios y finamente a manos de los grandes propietarios que controlaban el poder político y, en tercer lugar y a la postre la más utilizada, mediante la jurisdicción privativa de los alcaldes de aguas, los grandes adulados o aguatenientes defendieron el apropiarse de los excedentes de aguas provenientes de los nacientes de las medianías y cumbres que luego discurrían por los barrancos de donde manaban las aguas de los heredamientos iniciales (Macías \& Ojeda, 1989). Todo ello con la progresiva separación de la asignación del agua a la tierra. Este proceso culmina en la segunda mitad del siglo XIX y primer tercio del xx, aprovechando la legislación desamortizadora, con el impulso privatizador que se realizó mediante la apropiación por los grandes propietarios de las aguas superficiales de carácter público comunal y de propios de los recién creados municipios mediante dos procedimientos: a) un generoso régimen de concesiones de aguas públicas sobrantes propiciado por la Administración (Nieto, $1967)^{13}$; y b) la aprobación de numerosas licencias de aguas públicas continuas y discontinuas con fines agrícolas.

El número de solicitudes para obtener concesiones de aguas públicas se distribuyó a lo largo de tres períodos temporales de la primera mitad del siglo xx, en razón del aumento de las roturaciones de fincas para los nuevos cultivos de exportación introducidos en La Gomera (inicio: hasta la Primera Guerra Mundial; desarrollo: período de entreguerras; y culminación: con posterioridad a la Segunda Guerra Mundial).

En síntesis, la creación de las comunidades de regantes y las concesiones para el aprovechamiento de las aguas públicas sobrantes (continuas y discontinuas) para el riego fueron las variantes que desencadenaron la progresiva expropiación del agua comunal a los campesinos gomeros, fenómeno que quedó materializado en pocas décadas, tal y como se explicará en los siguientes apartados.

\section{EL PROCESO DE EXPROPIACIÓN DEL AGUA COMUNAL EN LA GOMERA EN EL SIGLO XX}

En una isla eminentemente agraria, como lo fue históricamente La Gomera, disponer del recurso agua era fundamental para el sostenimiento de la economía, tanto familiar como

13.Las concesiones eran autorizadas primeramente por los jefes políticos de acuerdo con la R. O. de 20 de junio de 1839; luego, por el Consejo Provincial de Canarias, siguiendo en su caso el procedimiento administrativo regulado en la R. O. de 14 de marzo de 1846 y R. D. de 20 de abril de 1860; la ley de Aguas de 1879 introdujo una regulación más restrictiva con objeto de evitar daños a terceros, ampliándose sus disposiciones con la orden de 5 de junio de 1883 y de 1901. 
general. Por ese motivo, durante siglos, la comunidad campesina isleña, mayoritaria ${ }^{14}$, trató de articular estrategias que le asegurasen el acceso al agua, de ahí los derechos de uso y aprovechamiento vinculados a la tierra. En La Gomera, la estrategia seguida fue la dula, el sistema de riego principal empleado en todos los barrancos de la isla, el cual pasaría, en el primer cuarto del siglo $\mathrm{xx}$, a ser sustituido por el turno de horario, una fórmula adaptada a las exigencias de los nuevos cultivos de exportación, principalmente al plátano.

\subsection{El sistema tradicional: la dula}

La dula es la expresión ${ }^{15}$ de una antigua forma de irrigación utilizada en el Levante español desde los tiempos de la ocupación árabe y que, conservada tras la Reconquista castellano-aragonesa, fue posteriormente implantada en Canarias con la colonización castellana (Furió, 2011; Guillamón, 2003; Hermosilla, Iranzo \& Antequera, 2012), desde donde se exportó en el siglo XVIII a San Antonio (Texas) (Glick, 1989: 124).

En La Gomera, la dula hace referencia al turno de riego adjudicado a cada parcela. En la terminología autóctona, la expresión adulamiento hace referencia a los días de riego por agrupamiento agrícola, un término que Reyes (1989: 32), siguiendo a otros autores ${ }^{16}$, relaciona con los heredamientos. Es un régimen caracterizado por la adscripción del agua a la tierra y establecido, principalmente, para una agricultura de subsistencia, en la que cada cuenca o unidad de riego disponía de su propio sistema de gestión de aguas independiente de las colindantes.

El orden de riego en agrupamientos agrícolas solía estar definido por unidades topográficas concretas (cauce, cañada, ladera, etc.) o por determinadas infraestructuras (atarjea, tomadero, etc.). Las parcelas que integraban esos espacios se regaban, generalmente, siguiendo una secuencia descendente, desde la parte alta (cabecera del barranco o inicio del naciente) a las cotas más bajas. En el marco de esta práctica, el espacio regable estaba definido y delimitado como un coto cerrado, en el que cada finca tenía una cantidad de agua asignada según la costumbre.Y esta agua estaba adscrita a la tierra, estaba vinculada a la parcela de riego y no al propietario del predio. Se trata de una tradición que sigue vigente en la isla.

14.El análisis de los padrones de población municipales de mediados del siglo xx destaca que el $76 \%$ de la población activa de La Gomera en ese momento se dedicaba a las faenas agrícolas.

15.Término que procede del árabe dawlaw, que significa «turno» (RuIZ RuIZ, 2013: 13).

16.F. M. de León y Falcón (1852). Memoria sobre el estado de la agricultura en la provincia de Canarias. 
La dula fue el sistema de riego más empleado en La Gomera, aunque desconocemos la fecha exacta de comienzo de esta práctica. Las referencias más antiguas que manejamos son las recogidas en la obra de Díaz Padilla y Rodríguez Yanes sobre el señorío en las islas occidentales, y que se remontan al siglo XVII. Las menciones a la dula se pueden encontrar, tanto en los mayorazgos como en los censos otorgados en esa centuria. En todo caso, consideramos que se tuvo que aplicar mucho antes, y que fue la práctica más empleada desde los tiempos de la colonización castellana hasta el primer cuarto del siglo Xx. A partir de entonces, dicho sistema de riego se vio afectado drásticamente, debido a la implantación del turno de horario y a las privatizaciones de las aguas comunales en los principales valles de la isla.

\subsection{La aparición de las comunidades de regantes: la vía expropiatoria vinculada al plátano}

El modelo agrario existente en La Gomera entre los siglos XV y XX nuca necesitó de un cambio de sistema riego. Los cultivos de exportación, aunque habían sido importantes desde el punto de vista comercial, no lo fueron tanto superficialmente. Tomando como referencia la extensión del regadío a mediados del siglo xx (periodo en el que su amplitud territorial debía ser mayor a la existente en décadas anteriores), se puede apreciar que la superficie que ocupaba seguía siendo bastante inferior a la del secano.

\section{TABLA 2}

Superficie en hectáreas según usos agrícolas, 1957

\begin{tabular}{lrcccccr}
\hline & Agulo & Alajeró & Hermigua & San Sebastián & Valle Gran Rey & Vallehermoso & \multicolumn{1}{c}{ Total } \\
\hline Regadío & \multicolumn{1}{c}{} & 83 & 156 & 184 & 138 & 125 & 765 \\
Secano & 99 & 195 & 34 & 480 & 252 & 444 & 1.504 \\
Erial & 161 & 171 & 654 & 561 & 1.435 & 6.421 & 9.403 \\
Montes & 23 & 134 & 290 & 401 & 577 & 751 & 2.176 \\
Total & $\mathbf{3 6 2}$ & $\mathbf{5 8 3}$ & $\mathbf{1 . 1 3 4}$ & $\mathbf{1 . 6 2 6}$ & $\mathbf{2 . 4 0 2}$ & $\mathbf{7 . 7 4 1}$ & $\mathbf{1 3 . 8 4 8}$ \\
\hline
\end{tabular}

Fuente: elaboración propia a partir del Catastro de Rústica de 1957.

Hasta el primer cuarto del siglo xx, los ámbitos del regadío se circunscribían a los fondos y desembocaduras de los barrancos principales, y a lugares próximos a las fuentes naturales de agua situadas fuera de los cauces. Se trataba, por consiguiente, de cultivos pocos exigentes en riego en comparación a los nuevos frutos que se pretendía implantar, sobre todo, el plátano.

A finales del siglo XIX se introdujeron en Canarias, de la mano del capital extranjero, principalmente británico, los monocultivos del plátano, primero, y los tomates, después; 
aunque en La Gomera parece que la secuencia fue a la inversa y retrasada algunas décadas con respecto a las islas mayores (Tenerife, Gran Canaria y La Palma). Según la historiadora Gloria Díaz, la empresa inglesa Elder E Fyffes Co fue la pionera y principal impulsora del cultivo y comercialización de los plátanos y tomates en La Gomera, comenzando en 1905 por Hermigua y extendiéndose, a continuación, por el resto de los grandes valles de la isla sobre terrenos arrendados a los grandes propietarios locales (Díaz Padilla 2008: 39, 40, 44). Posteriormente, se difundieron por otros espacios (Alojera, Taguluche, La Dama, lomadas de Alajeró, Playa de Santiago, Tecina y El Cabrito), lo que supuso una expansión territorial del regadío en la isla sin precedentes. No obstante, en La Gomera nunca llegó a los niveles alcanzados en las islas de Tenerife, Gran Canaria y La Palma (Rodríguez Brito, 1986: 273) ${ }^{17}$.

TABLA 3

Usos y tipos de cultivos de regadío en La Gomera, 1957

\begin{tabular}{lccccr}
\hline & Platanera & Hortalizas & Frutales & Cereal reg. & Total \\
\hline Agulo & 79 & 0 & 0 & 0 & 79 \\
Alajeró & 34 & 14 & 13 & 22 & 83 \\
Hermigua & 129 & 6 & 0 & 21 & 156 \\
San Sebastián & 28 & 36 & 0 & 120 & 184 \\
Valle Gran Rey & 43 & 0 & 0 & 95 & 138 \\
Vallehermoso & 83 & 12 & 0 & 30 & 125 \\
Total & $\mathbf{3 9 6}$ & $\mathbf{6 8}$ & $\mathbf{1 3}$ & $\mathbf{2 8 8}$ & $\mathbf{7 6 5}$ \\
\hline
\end{tabular}

Fuente: elaboración propia a partir del Catastro de la Riqueza Rústica de 1957.

La dilatación del mercado agroexportador internacional estimuló a los grandes propietarios locales para ampliar sus producciones fruteras, lo que derivó en sus acciones contra el sistema tradicional de riego (la dula). Inicialmente, intentaron apropiarse del agua de un modo transparente, pero esta estrategia no fructificó debido a su arraigo a la tierra. Por tanto, tuvieron que idear otra estrategia para conseguirlo, que fue la creación de las comunidades regantes, entidades a las que la ley de Aguas de 1879 permitía su aprovechamiento privativo.

17.Los datos del estudio del profesor Rodríguez Brito, tomados del Mapa Agronómico Nacional, se refieren a 1940, e indican que la extensión destinada a la platanera en La Gomera era de 197 héctáreas, frente a las 509, 1.894 y 2.158 de La Palma, Tenerife y Gran Canaria, respectivamente. La información para el periodo anterior, como ya hemos planteado más arriba, no existe disgregada por islas, sino por provincias o región canaria. 
A partir de estas corporaciones ${ }^{18}$, los grandes propietarios pudieron controlar el agua para riego, pues en ellas se debían integrar las aguas adscritas a cada comunero. Para formar parte de la comunidad, había que ser propietario de tierras, y una vez afiliado, se estaba obligado a ceder el uso del agua que le pertenecía (por derechos históricos o porque afloraba en algún manantial dentro de su finca) a la comunidad.

En el funcionamiento de estos organismos, el voto fue el mecanismo que permitió a los grandes propietarios controlar el agua de la comunidad y garantizarse un uso más favorable de ella. El voto era el requisito necesario para la toma de decisiones y la elección de cargos, y éste dependía de la superficie que concentrase cada titular de tierras ${ }^{19}$. Por tanto, a mayor superficie en propiedad, mayor capacidad de acción dentro de la comunidad en lo relativo, entre otras cosas, a la administración, explotación y repartición de las aguas (Reyes, 2002: 112-120).

Además, existía otro elemento a tener en cuenta para comprender la instrumentalización de las comunidades de regantes por parte de los grandes propietarios. Éste fue el caciquismo, es decir, el control político de las instituciones públicas (ayuntamientos y Cabildo insular) por dichos agentes ${ }^{20}$. En una sociedad rural como fue la de La Gomera, el control político tenía muchas implicaciones en el funcionamiento interno de las comunidades de regantes, donde muchos de sus integrantes (pequeños propietarios) accedían a apoyar las determinaciones de estos caciques para no verse perjudicados en posibles situaciones comprometidas con la Administración pública.

Por tanto, una vez que comenzaron a operar las comunidades de regantes, se pudo ejecutar el cambio de sistema de riego. Si con la dula el tiempo de riego estaba adaptado a la superficie de la parcela regable, con el turno de horario no sólo se adecuaba al tamaño, sino también al tipo de cultivo. De esta manera, las fincas de los grandes propietarios po-

18.Entendemos aquí el término corporaciones como una forma de gestión del agua llevada a cabo, en este caso, por una comunidad de regantes. De la forma antigua de dulas y heredamientos apoyados en el derecho consuetudinario, se pasó a una estructura orgánica con personalidad jurídica propia y apoyada en un funcionamiento administrativo, basado en unas ordenanzas (estatutos) y reglamentos que, entre otras cosas, regían la actividad de los organismos y cargos que la constituyeron (comunidad, sindicato, jurado de riegos y comisión revisora de cuentas).

19.En el caso de la Comunidad de Regantes de Hermigua, para conseguir un voto era necesario poseer entre $667 \mathrm{~m}^{2}$ y $1.667 \mathrm{~m}^{2}$ (entre 4 y 10 fanegas respectivamente según la medida local). A partir de ese primer voto, cada $1.667 \mathrm{~m}^{2}$ significaban un voto más. Los propietarios que no llegasen a poseer esa superficie imprescindible, podían unirse entre varios hasta alcanzar la extensión necesaria para ello (REYES, 2002: 118).

20. REYES (Ibíd.) lo analiza para el caso concreto de Hermigua, y nosotros dejamos constancia de este hecho para toda la isla en nuestra tesis doctoral (JEREZ, 2015: 212-217). 
dían disponer de mayor riego a tenor de la extensión y la producción platanera. Se consumaba en La Gomera una pauta de expropiación del agua comunal similar a la explicada por Ortega (2012: 82) en algunas demarcaciones de la Península, principalmente, en el Levante, con la expansión hortofrutícola.

Para aumentar la producción frutera, se roturaron zonas, hasta entonces marginales, en cada uno de los municipios, fundamentalmente en la costa, a través del sistema de sorribas $^{21}$. Los antiguos eriales, hasta entonces exentos de riego, fueron reconvertidos en fincas de regadío por los grandes propietarios, dado que al integrarse en una comunidad de regantes, pudieron asignarles una cuota de riego. Paralelamente, fueron ejecutando las infraestructuras hidráulicas y de comunicaciones necesarias, como los pescantes de Hermigua, Agulo y Vallehermoso en 1908, 1909 y 1911, respectivamente.

Esta expansión inicial de la nueva agricultura de exportación sucedió en las primeras tres décadas del siglo xx, e implicó, al mismo tiempo, un crecimiento demográfico en la isla sin precedentes ${ }^{22}$.

La aparición de las primeras comunidades de regantes en La Gomera tuvo lugar en el periodo comprendido entre las dos guerras mundiales. Según los datos que utilizamos ${ }^{23}$, la primera comunidad de regantes se creó en Hermigua en 1916. Esta naciente corporación fue impulsada por los grandes propietarios del municipio que tenían sus fincas de platanera en el tramo final del valle, motivo por el que la denominaron Comunidad de Regantes del Valle de Abajo.

En un principio, esta organización sólo gestionaba las aguas de los barrancos de Liria y Monteforte, donde sustituyeron la dula por el turno de horario. Por su parte, otros cauces (El Cedro, Aceviños, La Madera, La Meseta y La Calle) se mantuvieron bajo el régimen de la dula hasta 1938, momento en el que se aunaron a aquella para generar la Comunidad de Regantes del Valle de Hermigua ${ }^{24}$. Desde entonces, la mayor parte del

21. Sorribar es un vocablo canario que significa «romper o rebajar un terreno para prepararlo con fines agrícolas o para edificar».

22.Este crecimiento poblacional se mantuvo hasta mediados de siglo, momento en el que se abrió la válvula de la emigración, la cual se profundizó a partir de los años sesenta como consecuencia de la sobreexplotación campesina, la apropiación del recurso agua por los terratenientes y la apropiaciónprohibición de los usos del monte por parte del Estado. Ello supuso la crisis del sistema agrario insular en su conjunto.

23.Principalmente los expedientes del AHCIALG; también empleamos las fuentes hemerográficas y orales como complemento.

24.AHCIALG, 1968, exp. 4872, carpeta CR-4, documento de Junta General Extraordinaria, 
riego del municipio, a excepción de algunos pequeños ámbitos y enclaves marginales, quedó controlado por esa nueva comunidad y, por extensión, por los grandes propietarios de la localidad.

Agulo fue el siguiente municipio en el que se efectuó la expropiación del agua comunal. Aquí también fue la gran propiedad local la que pilotó hábilmente el proceso, a través de la figura del omnipresente cacique del pueblo: Leoncio Bento ${ }^{25}$.

Por las condiciones topográficas del municipio, los lugares más apropiados para cultivar el plátano quedaban reducidos a la zona baja, en las tierras ubicadas en torno al casco de Agulo y las laderas de Lepe, sectores en los que la familia Bento tenía bastantes propiedades $^{26}$.

La estrategia consistió en introducir el cambio de riego en el barranco de La Palmita, cauce que abastecía de agua a la zona baja. De este modo, en 1928, Leoncio Bento, entonces alcalde del municipio, movilizó a los regantes que se abastecían de las aguas públicas que discurrían por ese barranco y fundaron la Comunidad de Regantes de las aguas de Agulo $^{27}$. Esto implicó que los diferentes nacientes y las aguas pluviales que fluían por aquella cuenca quedaran bajo su gestión.

Por esas mismas fechas, en Valle Gran Rey también se modelaba el proceso de expropiación del agua comunal. Con un inicio similar al ocurrido en Hermigua, los agroexportadores locales de la costa se organizaron para operar el cambio de riego, tal y como se había hecho en los valles del norte. La nueva organización del mapa administrativo del municipio, que se había realizado en 1928, supuso la integración de varios lugares que

01/05/1965, pp. 2-3. Para hacernos una idea de los recursos hídricos de la zona, ReYEs (2002: 112) indica que la cuenca de Hermigua tenía aproximadamente en 1970 unos recursos hídricos de superficie de 1,6500 $\mathrm{hm}^{3}$ de agua. Asimismo, la Comunidad de Regantes de Hermigua (compuesta por 1.235 comuneros) riega unas 218 hectáreas, prácticamente la totalidad de las tierras de regadío del municipio, a excepción de unas tres hectáreas, que se mantienen bajo una dula.

25.Fue alcalde de Agulo en el período 1904-1908 y en 1927-1928. En 1921 obtuvo el acta de diputado por La Gomera dentro del Partido Liberal.

26.Según los datos del Catastro de Rústica de 1957, los distintos miembros de la familia Bento (que se encontraba en ese momento más disgregada a causa de las divisiones hereditarias) reunían una superficie de 23 hectáreas en esta zona del municipio (el 30\% del total), de las que el 38\% (9 ha), estaban dedicadas a la platanera, que era el uso mayoritario. Si a ésta cantidad le sumamos las 3 hectáreas destinadas al cereal de regadío, obtenemos 12 hectáreas ocupadas por el regadío, es decir, casi la mitad de las tierras que poseía dicha familia en su conjunto.

27.AHCIALG, 1928, exp. CR-1313, carpeta CR-2, Boletín Oficial de la Provincia, n. ${ }^{\circ} 112$, 19/09/1927. 
hasta entonces pertenecían al término de Vallehermoso. Entre ellos estaba el sector de Guadá, situado en la cabecera del barranco principal y punto donde nacía la mayor parte de las aguas que abastecían el valle (Reyes, 1989: 140; Perera, 2004, t. II, vol. 9: 112-113). Por tanto, al incorporarse este sector al municipio de Valle Gran Rey, esas aguas comunales quedarían sujetas a los designios de una comunidad de regantes del lugar, según los preceptos de la ley de Aguas de 1879. Y no tardaron en crearla. En 1929, un grupo de propietarios de la costa fundó la Comunidad de Regantes de la Zona Baja de Valle Gran Rey, y estableció un convenio con los regantes de la zona alta (donde existía la dula) en aras de una distribución equitativa del agua ${ }^{28}$. Pero este convenio no terminó de dar solución al problema de los derechos de uso y gestión del agua en la cuenca, dado que los regantes de la costa siempre tuvieron como objetivo controlar el agua que nacía en la parte alta del valle.

Desconocemos qué ocurrió a lo largo de los años treinta por la falta de información al respecto. Suponemos que se mantuvo el riego establecido, teniendo en cuenta que el desencadenamiento de la Guerra Civil paralizó las exportaciones. Pero el cariz que tomaron los acontecimientos producidos en la década siguiente nos induce a pensar que las antiguas disputas permanecieron latentes durante ese periodo.

Una vez finalizada la Segunda Guerra Mundial, y con la reactivación del negocio frutero, el afán productivo de los agroexportadores de la costa volvió a tambalear la «paz social» que se había alcanzado en 1929. Esto desembocó en los duros enfrentamientos entre la Guardia Civil y los campesinos de Guadá en 1947-1948, los cuales ocasionaron una víctima mortal a manos de la Benemérita.

El levantamiento costó una vida, algunos heridos y muchos encarcelados, pero también un triunfo de los campesinos de Guadá, pues consiguieron mantener un régimen de riego acorde a sus necesidades hortícolas. Este triunfo fue la expresión de la tenacidad de los pequeños campesinos de Valle Gran Rey, quienes se unieron (hombres, mujeres y niños) para luchar por lo que consideraban un derecho secular que los propietarios acomodados del valle querían arrebatarles para adecuarlo a sus intereses agrocomerciales. Fue éste un acontecimiento de notable valor histórico y social, al ocurrir en un momento de férreo control del Estado franquista, y al enfrentarse no sólo a los caciques de la localidad, sino, además, a un cuerpo como la Guardia Civil.

Finalmente, en agosto de 1948 se logró conciliar los dos sistemas de riegos en el valle a partir de la constitución de la Comunidad de Regantes de las Zonas Alta y Baja de

28.AHCIALG, 1929, exp. 1379, carpeta CR-2; 1958; exp. 2135, carpeta CR-2. 
Valle Gran Rey. De esta manera, en la zona alta se logró conservar gran parte de sus tradicionales derechos de riego, mientras que en la baja se aplicó el turno de horario al cultivo del plátano, sistema que se mantiene en la actualidad (Gómez Sal, Marín \& Mendaro, 1988: 129).

\subsection{La usurpación en los valles del sur: el caso de la comarca de Playa de Santiago}

A diferencia de lo ocurrido en los municipios del norte y en Valle Gran Rey, en las zonas del sur en las que se expandió el regadío comercial, el proceso de expropiación del agua comunal siguió por otros derroteros. Aquí, los grandes propietarios que estuvieron al frente fueron foráneos (de otras islas y del extranjero). Dos de ellos disfrutaban de un poderío económico incomparablemente superior a los agentes locales, de tal forma que, cuando decidieron invertir en La Gomera de cara al negocio agroexportador con la compra de tierras, se convirtieron inmediatamente en los mayores propietarios de la isla. Tales hacendados fueron el tinerfeño Álvaro Rodríguez $\mathrm{López}^{29}$ y el grupo noruego encabezado por la familia Olsen ${ }^{30}$, quienes se implantaron en la comarca sureña de Playa de Santiago en el primer cuarto del siglo $\mathrm{xx}$.

Junto a ellos, también hubo otros terratenientes que se asentaron en distintos lugares del sur apropiándose del agua comunal. Fue el caso, por ejemplo, del palmero Duque Martínez, quien pasó a sustraer el agua de aprovechamiento secular a los campesinos de la zona de Erque, para trasladarla a su finca de la costa situada en la lomada de La Dama, en el sector meridional del municipio de Vallehermoso.

Asimismo, otra de las diferencias de lo ocurrido en los municipios de sur con respecto a los del norte fue que, mientras en éstos el proceso de expropiación de las aguas comunales se materializó a través de las comunidades de regantes (órganos controlados por los grandes propietarios de la tierra), en el sur se consiguió mediante la solicitud de conce-

29.Álvaro Rodríguez López era un reconocido agente del capital comprador tinerfeño vinculado a las navieras extranjeras (como la perteneciente a los noruegos), lo que le permitió convertirse en el naviero más importante de Canarias en la primera mitad del siglo XX [...], pues tuvo una de las mejores flotas que han navegado entre las islas (DíAz LORENZO, 2004: 56).

30.Según los datos del catastro de 1957, que es la fuente que empleamos para el estudio patrimonial, Álvaro Rodríguez López acumulaba una superficie de 1.400 hectáreas, lo que le convertía en el mayor propietario privado de tierras de la isla (excluimos los ayuntamientos). Le seguía en orden el grupo noruego (recogido en esas estadísticas como Agrupación Noruega), el cual reunía 807 hectáreas. 
siones administrativas de aprovechamiento de aguas al Estado. Se trató de un procedimiento excluyente, dado que las concesiones otorgadas a los terratenientes foráneos implicaron una captación casi completa del agua comunal, lo que limitó enormemente el uso a los regantes tradicionales. Éstos no quedaron sujetos, ni tan siquiera, a un turno, tal y como ocurrió donde se implantaron las comunidades de regantes, sino al uso de las sobrantes de las concesiones otorgadas. Por este motivo, lo ocurrido en las cuencas del sur controladas por los propietarios foráneos tuvo mayor calado, fue más dramático que donde se crearon las comunidades de regantes; cuestión explicable, en buena medida, por el tipo de agente implicado.

En todo caso, con esta comparación no queremos difuminar la ambición de la gran propiedad local en sus ansias de controlar el agua comunal; antes al contrario. Su ambición generó muchos problemas al pequeño campesinado, problemas que antes no tenían y con los que tuvieron que convivir durante décadas hasta que la emigración se presentó como la vía de escape a la penosa vida que soportaban en el campo.

Lo que se desencadenó en esta parte de La Gomera no fue más que la expresión particular de lo que sucedió, bajo otras formas, en el resto de la isla al calor del negocio frutero. Pero la magnitud que adquirió en la comarca de Playa de Santiago no tuvo paralelismo en ninguna otra parte de la isla, por lo que queremos dedicar este apartado a su análisis.

Esta comarca es un espacio que no tiene unos límites administrativos definidos. La denominación de Playa de Santiago hace referencia, realmente, al enclave situado en la costa, pero que a lo largo de la centuria, por la importancia socioeconómica que adquirió al calor de la agricultura de exportación y la pesca, se articuló como el punto gravitacional de toda esta parte del sur de La Gomera. En un intento de delimitar dicha comarca, hemos incluido en su demarcación la cuenca hidrográfica Benchijigua-Imada-Santiago y las laderas que la flanquean en la costa, que es donde se desplegó la agricultura de exportación, base explicativa de los cambios que tuvieron que ver con el riego y aprovechamiento de las aguas en esta zona.

A comienzos del siglo xx, la comarca era un espacio marginal en la isla. Entre todos los núcleos poblacionales que la conformaban (en la costa, cuencas y laderas colindantes) ${ }^{31}$, no llegaban a 700 habitantes $^{32}$. La estructura económica era muy simple, apoyada

31.Laguna y Playa de Santiago, Tecina, Taco, El Cabezo, Pastrana, Lo del Gato, Benchijigua, Imada, Targa y Antoncojo.

32.En 1900 la población de derecho y hecho era de 648 y 620 habitantes, respectivamente (No- 
en una agricultura de subsistencia con cultivos de regadío y secano, y una escueta actividad pesquera. Pero su devenir cambiaría en cuestión de pocos años debido al impulso de la agricultura de exportación y la pesca ${ }^{33}$.

\section{MAPA 3}

\section{Comarca de Playa de Santiago}

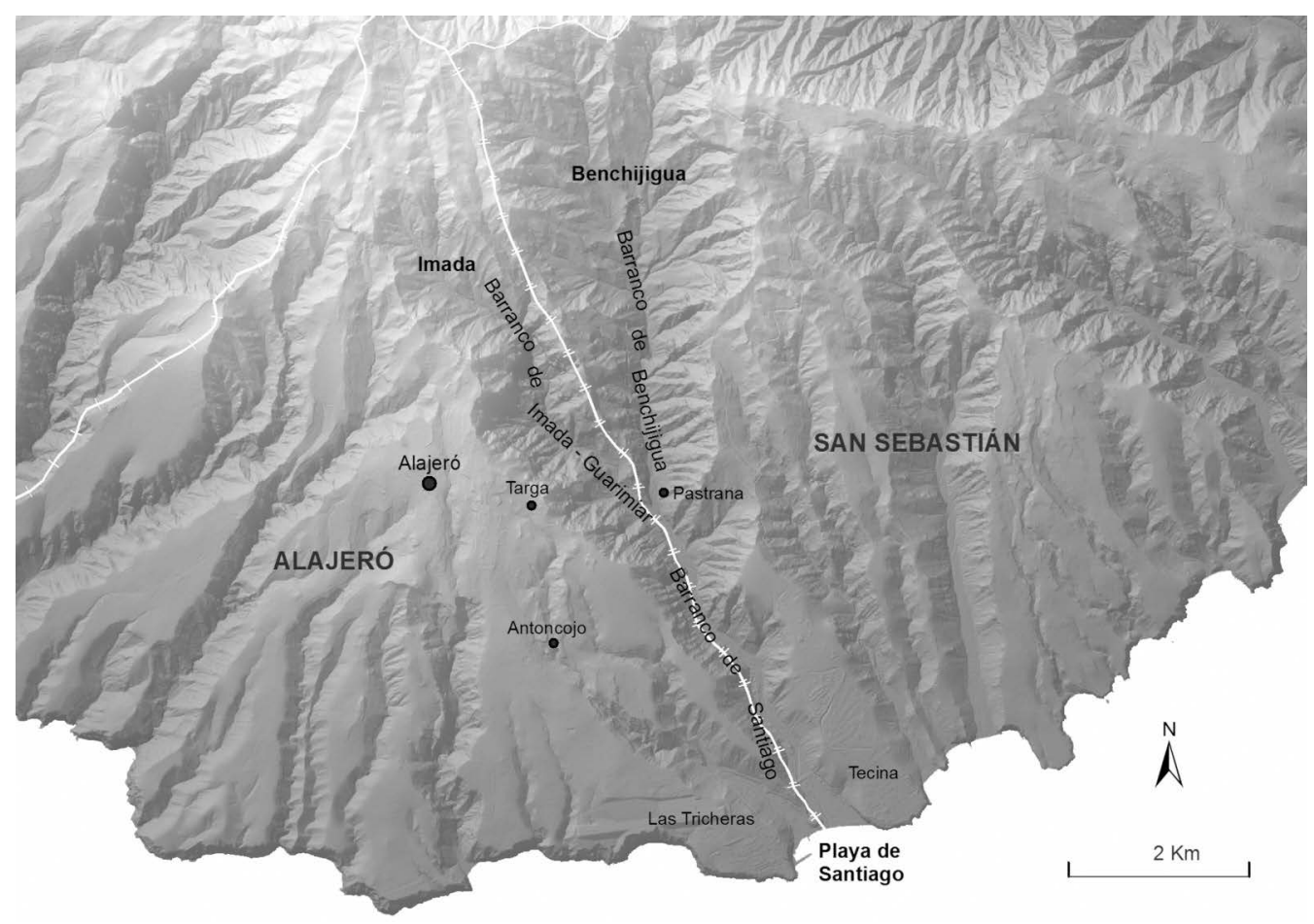

Fuente: elaboración propia a partir de la base cartográfica de Grafcan.

El punto de partida lo situamos en 1909, cuando la Sociedad Lomada de Tecina, compuesta por unos socios tinerfeños -entre los que estaba Álvaro Rodríguez López- y noruegos, adquirieron más de cuarenta hectáreas en la lomada de ese nombre, al oeste de Playa de Santiago.

Paralelamente a la adquisición de parcelas, los nuevos terratenientes fueron ideando la estrategia para disponer del agua con la que regar sus fincas, momento en el que el sistema de riego tradicional empezó a sufrir las acometidas de estos agentes.

menclátor de población).

33.En 1950 la población de derecho ascendía a 3.342 habitantes, y la de hecho a 3.287, el máximo histórico de la comarca (Nomenclátor de población). 
A finales de 1912 solicitaron una autorización para derivar las aguas públicas que discurrían por el barranco de Santiago hacia la finca de Tecina (continuas $=70 \mathrm{l} / \mathrm{s}$ y discontinuas $=200 \mathrm{l} / \mathrm{s})^{34}$. La proposición fue aceptada por el Gobierno Civil de la provincia e, inmediatamente, acometieron la construcción de un tomadero. Era el comienzo de las sucesivas pugnas con los regantes tradicionales, quienes manifestaban que esa concesión afectaba a los riegos que venían realizando desde tiempo inmemorial ${ }^{35}$.

La solución ideada por la empresa para mantener la paz social en la zona pasó por la formulación de convenios con algunos regantes del lugar, medida que aplicaría más adelante en diversas ocasiones.

La irrupción del conflicto bélico mundial en 1914 paralizó momentáneamente el proceso, pero en 1919 se reinició. En ese año entró en escena el grupo The Norwegian Canary Agricultura Company (Tecina) Ltd. (formado únicamente por socios noruegos, entre ellos, Thomas Olsen, el pionero del actual grupo Fred Olsen \& Co. en La Gomera), el cual sustituyó a la antigua Sociedad Lomada de Tecina, y para el que trabajaron como representantes locales los miembros canarios que participaban en esta sociedad.

Desde el comienzo, el consorcio noruego fue directo a resolver los problemas que sus antecesores tuvieron con el agua. En primer lugar, adquirieron la finca de Benchijigua (lugar en el que nacían las aguas que discurrían por el barranco del mismo nombre y su prolongación de Santiago) y, acto seguido, comenzaron a ejecutar la infraestructura necesaria (tomaderos y acueductos) para canalizar el agua desde ese punto (situado en las medianías) hasta las fincas de la costa emplazadas en la lomada de Tecina.

Estas actuaciones desataron rápidamente la inconformidad de los vecinos, propietarios y usuarios tradicionales del agua del barranco de Santiago ${ }^{36}$. Pero la iniciativa tuvo escaso recorrido, fundamentalmente por la existencia de convenios firmados con la empresa, y porque muchos de los vecinos trabajaban para ella. En esos convenios, el consorcio se comprometía a respetar el régimen tradicional una vez que comenzaran las de-

34.Las aguas continuas son las permanentes, que en La Gomera, debido a la ausencia de ríos, son las provenientes de los nacientes (afloramientos naturales de agua). Por su parte, las discontinuas son las procedentes de las precipitaciones.

35.AHCIALG, 1920, exp. 26, carpeta AL-1.

36.Según el nomenclátor de población de 1920, el número de habitantes en el barranco de Santiago, repartidos en diferentes núcleos, era de 644, por lo que nos podemos hacer una idea del contingente poblacional afectado por estas actuaciones sobre los recursos hídricos de la zona, de los que dependía la vida de todas ellas. En 1950, el número de habitantes ascendía a casi 1.200 personas, el máximo histórico. 
rivaciones de agua hacia Tecina, mientras que los regantes tradicionales daban su conformidad a las iniciativas que proponía la empresa ${ }^{37}$.

Pero la dinámica fue por otros derroteros. La cantidad de agua que necesitaba la sociedad para garantizar el funcionamiento de sus fincas en la costa implicaba, forzosamente, una alteración del sistema secular de aprovechamiento en toda la cuenca. Más aún, cuando el negocio agroexportador repuntaba nuevamente en Canarias. Por tanto, prosiguieron solicitando y obteniendo del Estado nuevas autorizaciones para derivar el agua a la costa.

El año 1923 fue el momento crucial de toda su estrategia, al conseguir una autorización a perpetuidad del aprovechamiento de 100 1/s de las aguas continuas y discontinuas que nacían en la finca de Benchijigua ${ }^{38}$, a la que se sumaron otros $67 \mathrm{l} / \mathrm{s}$. Con este hecho, todo quedaba dispuesto, a la vez que el sistema de riego tradicional expiraba irremediablemente.

Durante los años de la Segunda República parece que la situación en torno al agua en la comarca no sufrió cambios, a tenor de los datos que manejamos. Pero con el estallido de la Guerra Civil, el socio Álvaro Rodríguez López pasó a tomar la iniciativa, mientras que el grupo noruego, debido al encadenamiento bélico, paralizó sus negocios en la isla hasta después de la Segunda Guerra Mundial. De esta manera, el agente canario inició su andadura empresarial de forma autónoma en 1938, adquiriendo grandes extensiones de tierras en las áridas lomadas de Alajeró. A partir de entonces, las disputas por el agua también se extendieron a la cuenca de Imada-Guarimiar.

La expansión hacia estas nuevas áreas coincidía con los prolegómenos de la política agraria que el Estado iniciaba en 1939; primero, con la creación en octubre del Instituto Nacional de Colonización (INC) y, posteriormente, con la ley de Bases de 26 de diciembre para la Colonización de Grandes Zonas. Esta última normativa facilitaba a la iniciativa privada la creación de nuevos regadíos, oportunidad que tomó Álvaro Rodríguez López para extender el tomate en las nuevas tierras que había adquirido, y a las que abasteció con el agua sustraída de los barrancos de Imada (cabecera occidental del barranco de Santiago) y Guarimiar.

37. Convenios de 26 de marzo y de 19 de agosto de 1919 (AHCIALG, 1921, exp. 855, carpeta AP2), y de 4 de febrero de 1920 (AHCIALG, 1920, exp. 26, carpeta AL-1).

38.El aprovechamiento está inscrito en el Registro de la Propiedad (RPLG) bajo el número de finca 1583 del municipio de San Sebastián de La Gomera (RPLG, 1. 20, t. 254, f. 61, inscripción 25; AHCIALG, 1921, exp. 855, carpeta AP-2). 
Comenzaron, entonces, las adversidades para los usuarios tradicionales del agua en esta cuenca al modo de lo ocurrido en la de Benchijigua. Los campesinos del lugar fueron progresivamente despojados de gran parte de sus aprovechamientos consuetudinarios a favor del empresario tinerfeño, quien acaparó el grueso de las concesiones de aguas otorgadas para el riego de esta zona entre 1939 y 1960.

En 1939 obtuvo a perpetuidad la explotación de 100 1/s de las aguas discontinuas que discurrían por el barranco de Imada ${ }^{39}$, consiguiendo, un año más tarde, su ampliación con el aporte de las aguas continuas (las procedentes de nacientes).Y en 1944 obtuvo otra concesión más, en este caso, el aprovechamiento de 400 1/s de las sobrantes discontinuas del barranco de Guarimiar ${ }^{40}$.

\section{MAPA 4}

Vista parcial del parcelario de las empresas en 1957 y red de riego privada

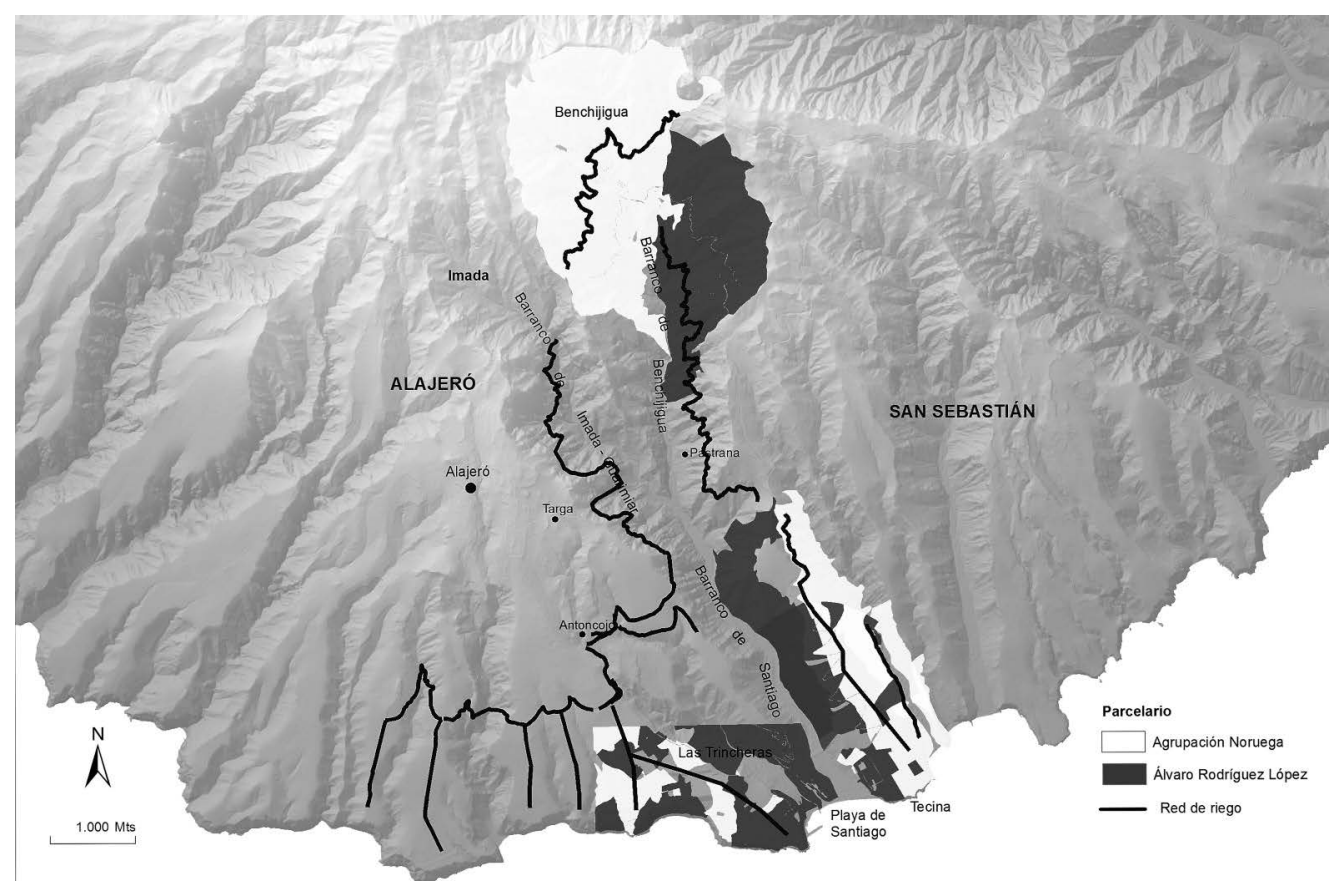

Fuente: elaboración propia a partir del Catastro de Rústica de 1957.

39.AHCIALG, 1939, exp. 2007, carpeta AP-5, memoria del proyecto «Aprovechamiento de 100 litros por segundo en el barranco de Imada con destino al riego de terrenos propios», p. 1.

40.AHCIALG, 1943, exp. 2907, carpeta AP-7, memoria del proyecto «Aprovechamiento de 400 litros por segundo en el barranco de Guarimiar», p. 2. 
Nuevamente, la oposición de los regantes tradicionales se hizo efectiva, pero con nulos resultados. La expansión del regadío proyectada por el agente tinerfeño tuvo el apoyo incondicional del Estado. De este modo, se consumaba la expropiación del agua en esta cuenca, al tiempo que se cerraba el círculo en la comarca de Playa de Santiago.

Con el paso del tiempo, la oposición de los regantes de las dos cuencas de la comarca (Benchijigua-Santiago e Imada-Guarimiar) fue menguando, hasta que terminaron por resignarse, pues, además de perder todas las reclamaciones realizadas a los distintos organismos estatales (Gobierno Civil de la provincia, Ministerio de Fomento y Ministerio de Obras Públicas), la mayoría pasó a trabajar como mano de obra barata en las fincas de ambas empresas; una situación que implicaba evitar enfrentamientos si se quería mantener el puesto de trabajo. Fue el incómodo destino que les deparó el interés de esos grandes propietarios que hicieron fortuna en La Gomera.

\section{CONCLUSIONES}

Partiendo del escaso conocimiento que existe sobre la cuestión del agua en La Gomera debido a la falta de investigaciones al respecto, con este artículo hemos intentado aportar nueva y más información sobre el complejo tema de la propiedad y la gestión del agua en la isla. En síntesis, lo que hemos expuesto es una parte del proceso de expropiación del agua pública comunal al pequeño campesinado por parte de los grandes propietarios de la tierra.

Como hemos visto a lo largo del texto, el sistema de riego tradicional (la dula), que había nacido al calor de los repartimientos de tierras en el proceso de conquista de la isla, fue sacudido en el primer cuarto del siglo xx para expandir la agricultura de exportación en la costa. Ese sistema secular estaba vinculado a un entorno definido por el minifundio y el autoconsumo, pero cuando se introdujeron los plátanos a comienzos de esa centuria, la práctica ancestral del riego fue sometida a cambio. Los promotores de esa alteración fueron los grandes propietarios de la tierra, grupo que, junto con el capital extranjero, introdujo y controló la nueva producción frutera, a la que se unió el tomate.

Esa variación implicó la desvinculación del agua de los campesinos, formalizándose dentro de los cauces de la «legalidad» en el momento en el que se constituyeron las comunidades de regantes (en la segunda década del siglo $\mathrm{xx}$ ) como entes de gestión del agua en los valles del norte y oeste, órganos que estaban controlados por los grandes propietarios de tierras. Asimismo, en el sur de la isla ese proceso no necesitó, ni siquiera, de esas entidades para monopolizar el agua. La comarca de Playa de Santiago es la muestra pal- 
maria de ello, a través de una expropiación-privatización dirigida por agentes foráneos y lograda con la colaboración del Estado.

\section{AGRADECIMIENTOS}

Los autores expresamos nuestros agradecimientos al Consejo Insular de Aguas de La Gomera por aportarnos todos los materiales de archivo necesarios para desarrollar esta investigación, así como, a los evaluadores anónimos de Historia Agraria.

\section{REFERENCIAS}

Batista, J. A. (2001). El agua es de la tierra: La gestión comunal de un sistema de riego del nordeste de La Palma (Los Sauces). Madrid: Ministerio de Educación, Cultura y Deporte.

Calatayud, S. (2016). Antes de la política hidráulica: La gestión del agua bajo el Estado liberal en España (1833-1866). Historia Agraria, (68), 13-40.

Consejo Insular de Aguas de La Gomera (2001). Plan Hidrológico Insular.

DíAz CRUZ, P. L. (2013). El agua en Canarias: Una aproximación historiográfica. Vegueta. Anuario de la Facultad de Geografía e Historia, (13), 43-64.

Díaz Lorenzo, J. (2004). Al resguardo de Anaga: De los correíllos al «fast ferry». Vol. II. Santa Cruz de Tenerife: Tauro.

Díaz Padilla, G. \& Rodríguez Yanes, J. M. (1990). El señorio en las Canarias occidentales: La Gomera y El Hierro hasta 1700. Santa Cruz de Tenerife: Cabildo Insular de La Gomera/Cabildo Insular de El Hierro.

Díaz Padilla, G. (2008). Pescantes de La Gomera: Testimonios de la arqueología industrial de Canarias. San Sebastián de La Gomera: Cabildo Insular de La Gomera.

FURIó, A. (2011). El patrimonio cultural valenciano: Una mirada desde la Historia. En J. Hermosillo (Dir.), Atlas del Patrimonio Cultural Valenciano (pp. 18-25).Valencia: Generalitat Valenciana/Ministerio de Medio Ambiente, Medio Rural y Marino.

GARRIDO, S. (2011). Las instituciones de riego en la España del este: Una reflexión a la luz de la obra de Elinor Ostrom. Historia Agraria, (53), 13-42.

GARRIDO, S. (2014). Water Management, Spanish Irrigation Communities and Colonial Engineers. Fournal of Agrarian Change, 14 (3), 400-418.

GLICK, T. F. (1970). Irrigation and Society in MedievalValencia. Cambridge: Harvard University Press.

GLICK, T. F. (1989). El termino árabe Dawla "turno de riego», en una alquería de las tahas de Berja y Dalias: Ambroz (Almería). En L. CARA (Coord.), El agua en zonas ári- 
das: Arqueología e historia: Hidráulica tradicional de la provincia de Almería (pp. 121141). Almería: Instituto de Estudios Almerienses.

Gómez Gómez, M. A. (2010). Gestión y propiedad del agua: Matices diferenciales entre las islas de señorío y de realengo. Boletín de la Real Sociedad Económica de Amigos del País de Tenerife, (1), 111-122.

Gómez Sal, A., Marín, C. \& MENDARo, C. (1988). Ecoplán para la isla de La Gomera. Madrid: Ministerio de Obras Públicas y Urbanismo.

Guillamón, J. (2003). Sistemas hidráulicos del Levante peninsular. En F. SANTos, C. SÁENZ \& M. Aguiló (Coords.), Ingeniería hispano musulmana: XII curso de verano de ingeniería civil, Toledo, 8 al 15 de julio de 2002 (pp. 247-270). Madrid: Colegio de Ingenieros de Caminos, Canales y Puertos.

Hardin, G. (1968). The Tragedy of the Commons. Science, 162 (3.859), 1.243-1.248. Hermosilla, J., Iranzo, E. \& ANTEQUERA, M. (2012). Los regadíos históricos valencianos, un patrimonio paisajístico propio del contexto mediterráneo. En J. M. GóMEz EsPÍN \& R. M. HeRvÁs (Coords.), Patrimonio hidráulico y cultura del agua en el Mediterráneo (pp. 179-188). Murcia: Fundación Séneca.

JEREZ, L. M. (2015). La organización territorial de La Gomera: Un ejemplo de subdesarrollo. Tesis doctoral inédita. La Laguna: Universidad de La Laguna.

MAASs, A. \& ANDERSON, R. L. (1978).... and the Desert shall rejoice: Conflict, Growth and Fustice in Arid Environments. Cambridge: MIT Press.

MACÍAs, A. M. \& OJEDA, M. P. (1989). Acerca de la revolución burguesa y su reforma agraria: La desamortización del agua. Anuario de Estudios Atlánticos, (35), 217-261. MACÍAS, A. M. (1990). Aproximación al proceso de privación del agua en Canarias (c. 1500-1879). En M. T. Pérez Picazo \& G. Lemeunier (Eds.), Agua y modo de producción (pp. 121-149). Barcelona: Crítica.

Macías, A. M. (2000). De Jardín de las Hespérides a islas sedientas: Por una historia del agua en Canarias, c. 1400-1990. En C. F. BARCiEla \& J. MELgAREJo (Eds.), El agua en la historia de España (pp. 169-275). Alicante: Universitat d'Alacant.

Martín-Retortillo, S. (1965). La elaboración de la ley de Aguas de 1866. Revista de Administración Pública, (32), 11-54. http://www.cepc.gob.es/publicaciones/revistas/ revistaselectronicas?IDR $=1 \& \mathrm{IDN}=32 \& \mathrm{IDA}=22122$

Nieto, A. (1967). Evolución de los Heredamientos en el siglo xix. En A. NiETo (Dir.), Estudios de derecho administrativo especial canario (pp. 101-147).Vol. III. Santa Cruz de Tenerife: Cabildo Insultar de Tenerife.

ORTEGA, A. (2012). De aguas, tierras y políticas hidráulicas en la España contemporánea. Vinculos de Historia, (1), 73-94.

Ostrom, E. (1990). Governing the Commons:The Evolution of Institutions for Collective Action. Cambridge: Cambridge University Press. 
Perera, J. (2004). La toponimia de La Gomera: Un estudio sobre los nombres de lugar, las voces indígenas y los nombres de plantas, animales y hongos de La Gomera. La Gomera: Aider Gomera.

Pérez Picazo, M. T. (2001). El agua y las comunidades de regantes. En A. L. LóPez VILLAVERDE \& M. ORTIZ HERAS (Eds.), Entre surcos y arados: El asociacionismo agrario en la España del siglo $x x$ (pp. 77-97). Cuenca: Universidad de Castilla-La Mancha.

Peris, T. (1997). La conflictividad hidráulica en el País Valenciano entre los siglos XIII y XVIII. Áreas, (17), 44-60.

QuiRANTES, F. (1981). El regadío en Canarias. Santa Cruz de Tenerife: Interinsular Canaria.

Reyes, A. (1985). Sistemas hidráulicos en la isla de La Gomera. Tesis doctoral. Universidad de La Laguna.

ReYes, A. (1989). Estrategias hidráulicas en la isla de La Gomera: Hermigua, Agulo y Valle Gran Rey (1900-1980). Santa Cruz de Tenerife: Cabildo Insular de Tenerife.

REYES, A. (2002). Estructura agraria, grupos de parentesco y política local en Hermigua (Gomera): Un estudio antropológico social (1900-1980). San Sebastián de La Gomera: Cabildo Insular de La Gomera.

RoDRÍGUEZ BRITO, W. (1986). La agricultura de exportación en Canarias (1940-1980). Santa Cruz de Tenerife: Consejería de Agricultura y Pesca del Gobierno de Canarias. Román, C. A. (1996). Estructura de la gran propiedad de la tierra en el archipiélago canario: Una valoración del Registro de la Propiedad Expropiable de 1933. Estudios Canarios. Anuario del Instituto de Estudios Canarios, (41), 99-118.

Romero, J. \& MATEU, J. (1991). Introducción. En F. Jaubert De PAssà, Canales de riego de Cataluña y Reino deValencia (pp. 7-101). Madrid: Ministerio de Agricultura, Alimentación y Medio Ambiente.

Ruiz Ruiz, J. F. (2013). Sistema de riego en la Vega de Granada: El mantenimiento de un paisaje agrario a partir de los repartos de agua de riego. e-rph: Revista Electrónica de Patrimonio Histórico, (12), 1-28. http://www.revistadepatrimonio.es/revistas/numero12/concepto/estudios/articulo.php 